\title{
Meckel Gruber syndrome - a single gene cause of recurrent neural tube defects
}

\author{
Deepthi de Silva', Devika Suriyawansa², Manel Mangalika ${ }^{3}$ and Dushyanthi Samarasinghe \\ (Index words: Genetic counselling, neural tube defects, multicystic kidneys)
}

\section{Summary}

Meckel Gruber syndrome (MGS), an autosomal recessive disorder characterised by posterior encephalocoele, multicystic kidneys and post-axial polydactyly should be recognised by obstetricians and paediatricians to counsel parents regarding the $25 \%$ recurrence risk. We report a consanguineous family with MGS affecting three infants.

\section{Case report}

The proband was seen during the 28th week of pregnancy when an ultrasound scan confirmed intrauterine growth retardation, oligohydramnios, an encephalocoele and cystic kidneys. A stillbom female infant weighing 1.2 $\mathrm{kg}$ was delivered at term. Post-mortem revealed an infant with a flattened nose, micrognathia, bilateral talipes equinovarus, limb contractures and bilateral post-axial polydactyly of hands. A skin covered posterior encephalocoele, enlarged multicystic kidneys and hypoplastic lungs were also found. This was the fourth child of first cousin Tamil parents, who have one surviving daughter. Two previous pregnancies resulted in infants who died soon after birth and had encephalocoeles.

\section{Discussion}

MGS is recognised as a cause of about $5 \%$ of neural tube defects (NTDs) (1). The cardinal features are occipital encephalocoele, post-axial polydactyly and renal cysts, but numerous other developmental abnormalities may be associated (1). The cardinal features are found in 50 to $70 \%$ of cases, and at least two are present in $20 \%$. Among affected siblings, up to $50 \%$ have identical features (2). Two genetic loci have been identified confirming genetic heterogeneity in MGS $(3,4)$.

MGS, with its $25 \%$ recurrence risk, must be differentiated from other NTDs which are usually polygenic and associated with recurrence risks of about $5 \%(5)$.
Periconception folate supplementation can reduce the risk of non-syndromic NTDs, but this is not the case with MGS (6).

Ultrasound scanning can diagnose MGS prenatally. As in this family, the awareness causes the parents to face a difficult choice between a technically illegal, late abortion (as termination of pregnancy for lethal foetal anomalies is illegal in Sri Lanka) or continuing a non-viable pregnancy. In spite of this, the gene carrier parents should be informed of the recurrence risks to enable them to make an informed reproductive decision about further pregnancies. They should be made aware of the $75 \%$ chance of a normal conception and the $25 \%$ risk of MGS.

\section{References}

1. Gorlin RJ, Cohen MM, Levin L S. Syndromes of the head and neck. 3rd Edition. Oxford: Oxford University Press, 1990: 7247.

2. Seller MJ. Phenotypic variations in Meckel syndrome. Clinical Genetics 1981; 20: 74-7.

3. Paavola-P, Avela K, Horelli-Kuitunen N, Barlund M, Kallioniemei, Idanheimo-N, et al. High resolution physical and genetic mapping of the critical region for Meckel syndrome and Mulibrey Nanism on chromosome 17q22-23. Genomic Research 1999; 3: 267-76.

4. Roume J, Genin E, Cormier-Daire V, Ma HN, Mehaye B, Attie T, et al. A gene for Meckel syndrome maps to chromosome 11 q13. American Journal of Human Genetics 1998; 4: 1095-101.

5. Harper PS. Practical genetic counselling 4th Edition. London: Butterworth and Company; 1998: 177-79.

6. MRC Vitamin study group. Prevention of neural tube defects: results of Medical Research Council vitamin study. Lancet 1991; 238: $131-7$.

'Senior Lecturer, Department of Physiology, Faculty of Medicine, University of Kelaniya, Ragama. ${ }^{2}$ Obstetrician and Gynaecologist, De Soysa Maternity Hospital, Colombo. ${ }^{3}$ Registrar in Pathology and ${ }^{4}$ Pathologist, Teaching Hospital, Karapitiya. (Revised version accepted 15 February 2001). 